\title{
12. CHANGING VIEWS ON ASSESSMENT FOR STEM PROJECT-BASED LEARNING
}

\author{
INTRODUCTION
}

Science, Technology, Engineering, and Mathematics (STEM) Project-Based Learning (PBL) integrates assessment methods across different aspects of learning experiences. While STEM PBL shifts the focus of attention from summative to formative assessment, a greater attention is given to the interpersonal domain. Because of the nature of STEM PBL, which is centered on developing real-world projects where students can apply their understandings of various concepts, authentic assessment underlies both formative and summative assessment tasks through technology, such as classroom response systems, and rubrics. Authentic assessment in STEM PBL helps students transition from an authority-imposed regulation to the self-regulation of their learning. Therefore, assessment in STEM PBL is inextricably interwoven with pedagogy through integrated assessment methods that develop the whole person, stimulate creativity, and foster individualized group responsibility.

The major focus of this book has been on the practical integration of knowledge so that students can demonstrate what they learn in meaningful ways to be academically successful. This chapter is concentrated on determining what students can do and on facilitating students to do more than what they think they can. The particular emphasis of this chapter is on formative assessment; though, making connections to grading and evaluating knowledge products are discussed as a necessity in the current age of accountability.

\section{CHAPTER OUTCOMES}

When you complete this chapter you should better understand:

- the nature of STEM PBL assessment

- various rubrics used in the development of STEM PBL

- complexities teachers face when assessing STEM PBL

When you complete this chapter you should be able to:

- develop an assessment plan that matches your selected learning outcomes for your STEM PBL activity

- communicate clearly with administrators and parents about valuing student learning and not just evaluating it

- assess student learning in terms of academic progress instead of meeting arbitrary decision points (e.g. 90, $80,70,60)$.

\section{OVERVIEW OF ASSESSMENT}

The Role of Assessment

STEM PBL requires a whole new perspective on what assessment means. As an integral component of STEM PBL, assessment holds the project components together, maintains student motivation for learning (Brophy, 2004), and provides both the teacher and the student with useful information about each student's learning (Kulm, 1994). In STEM PBL assessment, teachers need to change their focus from summative to formative assessment. When the focus is formative, (1) assessment is not seen as simply quantifying a product but is more concerned with the learning process (Ashcroft \& Palacio, 1996), (2) test scores or grades have minimal impact on the summative assessment of the students (Wright, 2008), and (3) students are keenly aware of their own learning processes.

Students are not accustomed to encountering the STEM PBL assessment. In typical teacher practices, assessment is synonymous with grading, which determines the success or failure at school. This typical 
approach to assessment leads students to strive to do well on tests in order to get a good grade rather than develop learning strategies through self-improvement and understanding. For students, an authority-imposed regulation of learning through grading precludes the interpretation of assessment as a means of feedback towards the desired learning objectives. For teachers, the typical approach to assessment emphasizes the common belief that teachers need to understand what students do not know so that teachers can adjust teaching content, teaching style, or the ways they assess learning to improve student understanding. Over the course of their education, students have already developed a preconceived notion of what assessment is and how it is done. Sometimes breaking the mold requires confronting student conceptions as well as shifting the practices of teachers.

Teachers need to be prepared for helping students with STEM PBL assessment. Based on our experiences with teachers, it is common at the beginning stages of PBL projects that teachers are faced with student reactions, asking for further clarification to their checkpoint assessment. To those teachers, our response is that students have to be taught how to interpret a rubric, how to interpret the teacher's comments, and that a formative assessment is meant as a checkpoint rather than a grade. It is also common that students are often turned off by poor grades at the initial stages of STEM PBL, so it is paramount that the teacher set the stage by discussing how formative rubrics are used and that rubrics are designed to help students identify the areas for improvement rather than to evaluate their success or failure. STEM PBL's new perspective on assessment requires a change in both teachers' and students' views on assessment.

\section{Formative and Summative Assessment}

There are two broad categories of assessment: Formative and Summative. Formative assessment provides students with regular feedback to regulate their own learning processes, whereas summative assessment primarily concentrates on evaluating the learning that has taken place following a predetermined instructional period. In the most general terms, almost any assessment can be used in a formative or summative way, albeit, some assessment tasks, such as multiple-choice tests, provide only limited information.

Summative STEM PBL assessment tasks are ideally planned concurrently with lesson development. It is, however, not unusual that preplanned rubrics are modified or new rubrics are created during the later stages. In this perspective, summative assessment is not relegated to the last day of the instruction. They can occur in smaller increments throughout the instruction. Teachers may choose to use short summative assessment tasks to guide students toward an improvement in collaboration with other team members by emphasizing the sense of individual accountability or toward a development of their content knowledge. Yet, such short summative assessment tasks should be accompanied by an advanced preparation of the students to the tasks rather than come as a surprise. As teachers would not be happy to have their teaching assessed without preparation or without knowing the criteria on which their teaching was assessed, using surprise summative assessment demoralizes students, diminishes their intrinsic motivation, causes discontinuity in group and individual learning, and can even break down the learning process extensively. Summative STEM PBL assessment should only be used after closely aligned formative assessment tasks are introduced to the students.

The formative STEM PBL assessment encompasses an accumulation of learning artifacts, which are assembled by students through clear and explicit directions from the teacher. Teacher-driven directions align the expected learning outcomes to the STEM PBL projects, while the artifacts are used as summaries of student knowledge or are knowledge products that depict a richer and more complete picture of what students have learned. In this regard, formative STEM PBL assessment should be a means for helping students apply their knowledge, thereby owning the knowledge rather than acing the tests. Thus, the formative STEM PBL assessment must move beyond evaluating student success in spitting out formulas.

In the age of accountability, success in multiple-choice tests still continues to be an important benchmark, measuring the effectiveness of teaching for tests. By focusing on critical assessment of students' progress in thinking through writing about what they learn and why they believe that they learned, formative assessment, which is empowered by such writing and reflection tasks, is more likely to lead students to be flexible with their knowledge (Boaler, 1998). Being flexible with their knowledge may help students develop certain testtaking skills, such as critical-reading skills that may help students develop the ability to better comprehend the readings presented in multiple-choice items on high-stakes state tests.

STEM PBL assessment evaluates both individual and group performance. It is important to match the formative assessment to the learning activity and the setting in which the learning takes place. For instance, individualized formative assessment of a group activity is less productive than a more encompassing and group-based assessment of learning. If students pursue learning individually, the group-based assessment may create dissonance with individualized learning and, thus, have a negative impact on student learning. For group-based assessment, if group membership is heterogeneously assigned, less customization of the 
assessment is required. When students are randomly or self assigned to groups, the assessment needs to be modified for each group's personality and academic idiosyncrasies. In cases where a high degree of customization occurs, groups may only demonstrate one specific learning goal of the STEM PBL as compared to students with less customization, who may be able to produce more comprehensive artifacts (see Figure 1). Similarly, the content is an essential variable that should be accommodated when designing the assessment. Some content is more easily assessable by some methods than others. For example it is a challenge to assess knowledge level content through creative assessment tasks. Thus, it may be difficult to assess content at the analysis or evaluation levels.

In short, formative assessment can differ based on several aspects of the STEM PBL environment, including:

- The setting (e.g. group or individual)

- The content

- Outcome expectations

- Allotted time frame

- The time students spend on the activity

- Constraints in the design brief

- Criteria

\section{Authentic Assessment}

Authentic assessment is the most complicated assessment method compared to other formative and summative schemes. Despite the lack of an agreed definition, there is a consensus among educators that authentic assessment tasks should focus on the knowledge products, which make the assessment relevant to the learner through real-world applications. Authentic assessment matches the content being learned and knowledge products with student interests guided by clearly defined outcomes. Examples of authentic assessment can include tasks as simple as students listing what they learned to get to a certain stage of the project or may be as complicated as filing a report of their progress and the steps involved in solving the problem. Authentic assessment fits into various aspects of STEM PBL in different degrees. For example, when assessment of procedural skills is the focus, authentic assessment is less relevant compared to the situation when the goal of assessment is to understand how students apply those procedural skills in realworld contexts. Another example is the "just in time assessment," which is a form of authentic assessment that utilizes technology. In one "just in time assessment" model, the tablets (e.g., iPads or Android-based mobile technologies) can be used, casting in the role of a data collector. The tablet easily captures student performance as a video and audio file, which can be used by the teacher to digitally record information into rubrics and made immediately available to the students. Just in time assessment is instantly performed by the teacher with minimal delay between the time that the assessment is performed and the time that students received information regarding their progress. Another just in time assessment example is the classroom response systems or classroom clickers (Duncan, 2005). Clickers provide the teacher with the opportunity to carefully play assessment, be it alpha numeric (the students type in a response), multiple choice, or numeric. With the help of the clickers, all students simultaneously participate in the learning process through both group and individual feedback. The group feedback can help the teacher make decisions about how the rest of the lesson will proceed. In return, students get a firm understanding of what the whole class understands and their corresponding learning level compared to peers. Because the identities of each individual are masked, students can only see the individualized feedback provided to them while the feedback to their peers remain anonymous. These forms of just in time assessment can be powerful in differentiating STEM PBL instruction from more traditional practices in a cost-effective way (Cavanaugh, 2006). Just in time assessment methods clarify the utilization of authentic assessment methods in the digital domain (see Chapters 8 and 9 on technology).

The Venn Diagram in Figure 1 categorizes the assessment methods explained in this chapter, some of which are more closely aligned to the intent of PBL than those peripherally associated. 


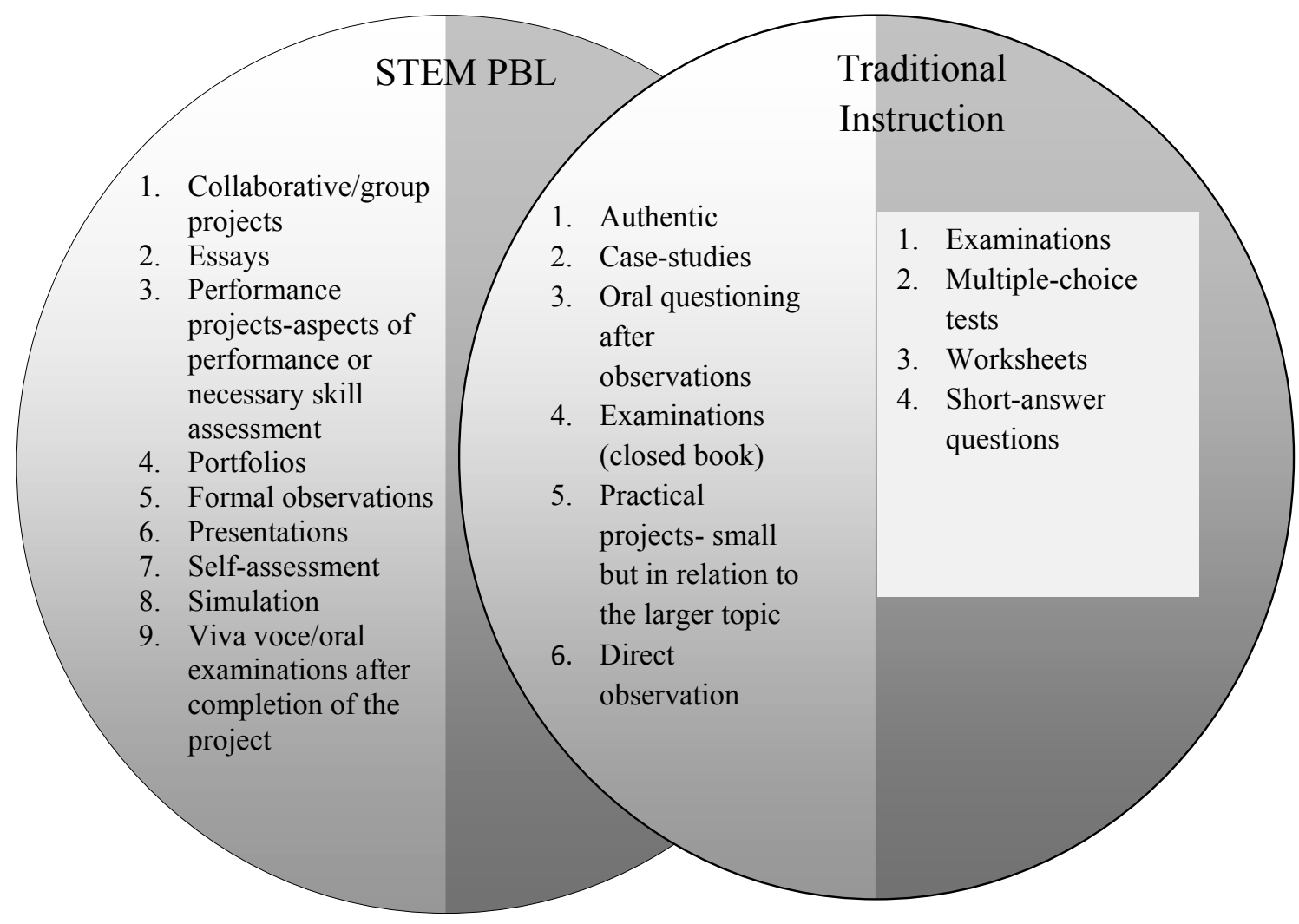

Figure 1. Comparison of assessment methods in STEM PBL and traditional instruction

\section{STEM PBL ASSESSMENT}

It is essential to integrate assessment and instruction in each STEM PBL lesson (Solomon, 2003). In the practical design of STEM PBL, the standards are clearly delineated so that assessment and instruction are intertwined. If teachers are keenly aware of the standards in their content area, then they can base their students' expectations on these standards and develop a STEM PBL environment that addresses these expectations. It is not necessary for the teacher to predetermine every aspect of the assessment methods to be used with the STEM PBL at the onset. Different assessment methods may be chosen after the initial selection of standards and perhaps even during the actual STEM PBL activity because assessment needs to be aligned with the learning environment. For instance, teachers can adjust the assessment method based on the setting because the assessment of the same content or standard can differ depending on whether learning occurs in groups or individually. When students learn in group settings, it is important to respect the group intelligence and assess in group settings with individual accountability. We present some examples of common rubrics as well as other examples and helpful tools in the Appendix of this chapter, which might be helpful to teacher in setting up their STEM PBL environments.

\section{Individual Accountability}

There are several accountability strategies that attenuate and facilitate group intelligence, yet encourage individual accountability at the same time. Peer assessment is one of those strategies that can provide the teacher with valuable insights about individuals' contributions to group intelligence. Further, setting up requirements, where students are randomly or pseudo randomly selected by the teacher, may explain the group's results so that the team's score is in part based on that person's individual responses. Reflection is another way to gain insights into individual performance. When the teacher uses reflection strategically, 
students can respond to questions about what would have improved the project, what would have improved the group's product, and how could their performance have changed to improve the quality of the deliverable. These questions can yield surprising insights about both the respondent and the team members. There are several examples contained in Appendix Q and R.

To help guide individual accountability, teachers may consider the use of contracts, both social and intellectual to establish common goals (common to the teacher and students) that clearly articulate expectations. The contracts can be agreed between groups when it is group behaviors (whether those behaviors are social or intellectual), between a group member and his or her group, or between the teacher and an individual group member or some members. Appendix $\mathrm{O}$ provides an example of a completed contract and several other contract types that can be used or modified to meet specific classroom and instructional needs.

Additionally, it is important to use individualized assessment that mirrors assessment tasks at the state level because students need to be able to demonstrate their learning on high-stakes testing formats, too. As long as schools, teachers, and student performances are measured with high-stakes tests, any educational innovation that fails to provide measurable impact on high-stakes assessment is doomed. Therefore, it is paramount to achieve an equilibrium between authentic and high-stakes assessment when considering the individual accountability. In a STEM PBL environment where the instruction focuses on designing, constructing, and synthesizing, it is important that assessment is similarly focused and that sufficient weight is given to these concepts as opposed to the high-stakes variety. One effective way to reflect student accountability in authentic assessment is through the careful design and application of rubrics.

\section{Development of Rubrics}

This book contains many rubrics, which are designed to provide educators with important guidance. Some of the rubrics are tried and tested for many years while some are newer. However, all are developed, used, and shared by the teachers we work with. Rubrics should be used with an important principle in mind that teachers should always prepare students before they use rubrics in class. Rubric use and grading has to be taught just like any other classroom practice so it can become the routine and not the exception. It is our honest goal that the included rubrics are viewed as intellectually stimulating and they prompt you the reader to try your hand at developing the rubrics you will use in your classroom to facilitate student learning and to stimulate creativity and in-depth STEM learning.

Rubrics are one means for providing students with formative and summative feedback about their learning processes. Rubrics can help teachers to evaluate students' learning efficiently (Andrade, 2000). Rubrics also provide guidance for students throughout the self- and peer-assessment processes (Andrade, n.d.). The specific and clear criteria identified in rubrics are particularly helpful for those professionals who are not teachers and thus not familiar with assessing student performance as they evaluate projects. A well-designed rubric contains components that reflect the specifics of the standards and conceptual generalities of an activity as well as intangible aspects like those reflected in the Secretary's Commission on Achieving Necessary Skills Report (2000). Various attainment degrees of the learning goals are specified in the rubrics (Andrade, n.d.). Rubrics should also provide sufficient information to help students understand what they know and do not know and some guidance about what they need to learn (Zimmaro, 2004).

\begin{tabular}{|c|c|}
\hline Rating & Brief Description \\
\hline 1. Nascent & Student displays preliminary knowledge and skills related to the learning task. \\
\hline 2. Constrained & Student displays limited knowledge and skills related to the learning task. \\
\hline 3. Developing & Student displays a developing level of content and concepts related to the learning task. \\
\hline 4. Commendable & $\begin{array}{l}\text { Student displays functionally adequate attainment of the content and concepts related to the } \\
\text { learning task. }\end{array}$ \\
\hline 5. Accomplished & Student displays mastery of the content and concepts related to the learning task. \\
\hline 6. Exemplary & $\begin{array}{l}\text { Student displays a novel or personal level of mastery of the content and concepts related to the } \\
\text { learning task. }\end{array}$ \\
\hline
\end{tabular}




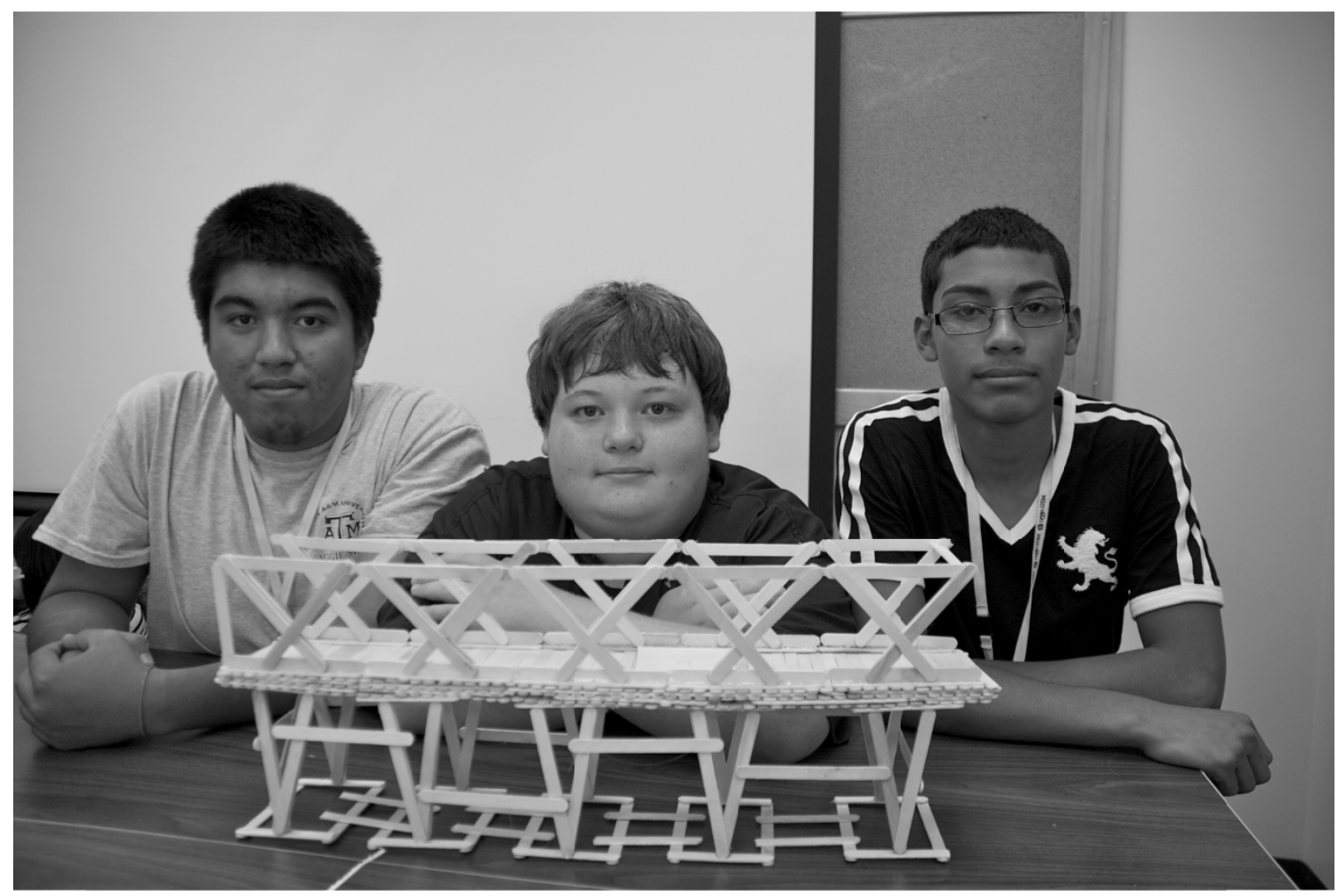

The rubric's scale can be closely related to the grading system or be one that obfuscates the relation between the scale score and the A to F grade equivalency. For example, a rubric can either be interpreted by point value and the points converted to a percentage score, or the six-point mastery rubric can be interpreted directly from A+ to F. Contrarily, a rubric can be based on a three- or four-point scale that does not align well with the conventionally-based A to F grading scale. An even number of ratings (such as four or six) precludes a midpoint decision on the part of the rater. This is often considered desirable. What is most important when designing a rubric is to assign more weight to the critical and important aspects of the task while placing less emphasis on things tangential to the clearly-defined outcomes.

\section{SAMPLE GENERIC RUBRIC}

Note. This rubric meets some of the tenants of rubric design, but from this rubric, the student would not have sufficient information about the knowledge gaps but just that he or she has gaps. To improve the rubric one could replace the words knowledge and skills or content and concepts with specific knowledge and/or skills necessary to the learning outcome.

Rubrics are an essential component of PBL that serve different purposes for those who are involved in the assessment process both at the stage of the rubric's development and its utilization during the evaluation. There are many stakeholders involved in the assessment process and the whole group should have some level of responsibility in the development of rubrics, including students, peers, the supervisor (teacher), and possibly even external evaluators such as other content-area teachers, administrators, coaches, or interested community members. When all stakeholders are involved in rubric development, they not only understand the criteria but also own them.

The use of rubrics by students through teacher modeling can help them develop important self- and peerassessment skills. However, in urban schools it is often difficult to enculturate self- and peer- assessments and teachers can find the enculturation process to be time consuming to attain the positive impact that these assessments are intended to achieve. However, some groups of students and/or school cultures are less resistant and teachers can be surprised by how rapidly students own the self- and peer-assessment methods. Sometimes students may be overly critical whereas at other times they are overly accommodating. It is important to model critical feedback (Falchikov, 1995) that is both honest and constructive. Students should understand that to identify a weakness without an accompanying suggestion for improvement does not foster intellectual development. To foster the development of self- and peer-assessment, it is important for students 
to (1) be involved in the development of rubrics, (2) be reflective by learning to self-assess, (3) receive critical commentary on their assessment of peers.

The enhanced understanding of learning goals and assessment criteria help students to develop metacognitive awareness and an intrinsic motivation (Peckham \& Sutherland, 2000). Students who regularly engage in PBL activities should be able to thoughtfully answer:

- How can I tell if I have learned

- Does the learning serve my current needs?

- Did I learn it in a way that I will be able to use it in the future?

- Will I be able to transfer this learning to new situations?

- Do I know what I do not know?

- Do I have the necessary foundation to learn more?

\section{Self-Regulation}

Explicit assessment helps students to self-regulate their behavior. Two different levels of self-regulation are present when students are integrally involved in the assessment process. The first level of self-regulation emerges as students co-develop rubrics for assessing various aspects of the PBL. Through involvement in the development of the rubrics, students establish ownership of the assessment model and clearly understand of what aspects of learning will be evaluated and how (Bray, 2001). This process will allow students to decide the degree to which their artifact meets expectations. This thorough understanding of the rubric can guide students as they implement self-regulation to plan their learning activities to achieve the objectives of the rubric. Thus, involving students in the development of rubrics fosters a sense of self-determination as they feel the agents of their own learning.

The second level of self-regulated behavior takes place when students learn peer- and self-assessment through the application of the rubrics they develop. As students do self-assessment, they get to know their areas of weakness and strength and allocate their effort to different areas of the learning objectives accordingly, thus holding themselves responsible. Students also start to align the requirements of the rubric with their learning process and desire to meet the requirements for their own benefit and purposes rather than merely meet the requirements of the teacher. Peer-assessment also could be a function as an information for their own learning, especially when assessment focusses on the development of particular skills in a noncompetitive environment. Informational feedback could further enhance students' self-regulation. This implementation of this second level of self-regulation may require several attempts and clarification by the teacher. Although the application of the rubric to assess a student's own learning and behavior may be difficult initially, repetition will lead to success and the student will eventually develop an appreciation for the assessment and value for the learning task.

\section{Formative Assessment of Teacher Enactments of PBL}

It is important to include the teacher in a chapter about assessment. The teacher too, should participate in being formatively assessed in his or her enactment of STEM PBL. We have included a sample document, which was developed by Aggie STEM team. The Aggie STEM teacher assessment instrument follows from our STEM PBL model as well as professional development training program. However, this teacher assessment instrument should never be used as a summative assessment of teachers. The document is designed to provide criteria specific information (Stearns, Morgan, Capraro, \& Capraro, 2012).

In order to improve the quality STEM education classes, which are designed to encourage conceptual development (i.e. PBLs), teachers need feedback and support, too. "There is considerable evidence from different studies suggesting that how teachers behave in the classroom, the instructional approaches they employ, significantly affect the degree to which students learn (Van Tassel-Baska, Quek, \& Feng, 2007, p. 85). In fact, research shows that ineffective teachers can depress student achievement in mathematics by as much as 54\% regardless of students' abilities (Sanders \& Rivers, 1996). Without some form of classroom observation, teachers' assimilation of professional development ideas cannot be assessed and continuous improvements may be compromised (VanTassel-Baska et al., 2008). Observations can be either peer or professional in nature, but the observer needs to provide feedback to the educator so he or she may evaluate and adjust their teaching to benefit students (Patrick, 2009). See Appendix S for an example. Therefore, to ensure translation of any professional development into classroom practice, assessment must be present in some form during actual teaching activities. When carefully aligned with the professional development, a 
classroom observation instrument can be an effective tool for providing feedback about assimilation of PD teaching strategies.

An effective way of evaluating teaching behaviors is with the use of a specifically designed observational instrument (Guskey, 2002; O’Malley et al., 2003; Simon \& Boyer, 1969). An observation tool can yield a descriptive account of targeted performances. This can be achieved with a conceptual rubric that contains a numeric range of descriptors for each predetermined objective. Observational data can also be structured with a frequency-counting system, or coding system (Taylor-Powell \& Steele, 1996). Observational tools can serve to monitor progress toward increasing a desirable trait or diminishing an undesirable behavior based on some theoretical framework. For example, The Aggie STEM teacher assessment instrument includes a category: "The teacher worked with members of all small groups," noting that a teacher who did this well, a score of 4 or 5 would likely provide confirmation that the actions were noteworthy and meritorious and might likely reinforce the practice. However, assigning a low score of 1 or 2, and noting in the discussion with the teacher that "Too much time was spent only one single group, resulting in not checking in with or visiting with other groups. This resulted in some students not making as much progress as others toward the completion of the project," would likely to identify the issue, describe the condition, and the effect. Thus, with all these points taken together, the teacher has a solid structure for altering instruction to meet the intent of the category. The information gained through an observation tool can also be used for teacher reflection and to customize subsequent professional development. See Project-Based Learning Observation Record (Stearns et al., 2012) in Appendix T.

The Aggie STEM teacher assessment instrument was specifically created to evaluate observable teaching and learning objectives when teachers develop and implement STEM PBL activities in their classrooms. Teachers being evaluated with this instrument should have participated in sustained professional development (5 or more full days) focusing on STEM PBL. The professional development should focus on each of the measured objectives. Both the observers and the teachers should be trained on the components and purposes of the instrument. The instrument contains twenty-two items organized by six objectives. The objectives include: (a) PBL Structure, (b) PBL Facilitation, (c) Student Participation, (d) Resources, (e) Assessment, and (f) Classroom Learning Environment. The number of indicators under each objective varies. Each indicator is evaluated on a scale ranging from 1 (no evidence) to 5 (to a great extent) with the observer justifying every score assigned to each item. Occasionally, an item will not apply to what is taught during a particular observation. When this happens or when the observer is only present for part of a PBL activity, a welldocumented lesson plan can provide insights and further details. The observer may still choose to indicate that a particular behavior was not applicable or not observed during the class period. Finally, the authors of the instrument at the Aggie-STEM Center encourage you to seek professional development prior to using it and to participate in an observers' workshop for teachers, who are already expert STEM PBL implementers, to learn to provide constructive-formative feedback and to carefully rate the teaching enactments.

\section{GUIDING THOUGHTS FOR TEACHERS ABOUT PBL ACTIVITIES AND ASSESSMENTS}

- Think about the content you teach. Think about what makes your content area and the assessments you traditionally use distinct from assessments in other content areas. Consider the changes that PBL requires in both teaching practices and assessments (Moursund, n.d.). A sample project development rubric is included in Appendix U.

- Think about how students learn. Much is known about the value of metacognition, self-assessment, and reflection on student learning. Do you think self-assessment is a valuable attribute for students who enter the workforce in a field related to your content area? How important is it in your content area of field to learn to assess one's own work and learning and that of peers or co-workers (Moursund, n.d.)?

- Think about your PBL. Critically examine your PBL and the lessons or activities and comprise it. Did the PBL cover the standards and objectives in your curriculum? Did you align assessment with your standards and objectives? Did you balance formative versus summative assessments? Think about provide useful formative feedback within the constraints imposed by the length of your instructional time allotment. How will you ensure the feedback is timely so students' efforts can reflect this information before the next assessment occurs (Moursund, n.d.)?

- Think about PBL versus traditional instructional practices. Consider the substantive adaptations or modifications you need to make in the structure of your curriculum and teaching practice. What aspects of PBL attracted you to make the effort and go through these changes (Moursund, n.d.)? If you are satisfied with the results of your current teaching practices, then one reason to implement PBL is to infuse the social responsibility so prevalent in PBL. Perhaps you are ready to try something new that will provide you a new challenge and add rigor to your activities to build on previous successes. You may have considered that times 
have changed and students will need to be prepared to thrive in a STEM world where the ability to creatively solve problems in dynamic and fluid situations abound. Regardless, students who are preparing to enter college will benefit from their experiences with PBL, and those students who do not participate in postsecondary education will develop a deeper and more salient understanding of the working world that they will enter. All students will have the opportunity to develop the cooperation and collaborative skills that are in demand regardless if they become factory workers or engineers.

\section{PBL SAMPLE AND ASSESSMENTS}

In the "Who Killed Bob Krusty?" PBL (see Appendix V), the scenario contains all the salient information that a student needs to successfully engage the problem. The activity integrates calculus and science with a forensic science and criminology spin. There are important skills need to be assessed before the start of the project and then again after the completion of the project. In this PBL, students are given the same assessment form before and after the activity. The pretest serves as one formative assessment. It provides students with a structure about what they are expected to be able to do upon completion of the PBL. For teacher, the assessments provide insights about students' strengths and weaknesses so that the teacher can adjust the PBL process to meet students' needs, such as providing whole-group instruction on specific topics. The posttest provides a direct measure of how much improvement was achieved through the PBL. Another summative assessment may be included, such as asking students to keep a daily journal where students can reflect on their learning, record their thought processes during the PBL, and discuss what mathematics they need to employ or learn more about.

This activity can facilitate incorporation of knowledge from additional disciplines. For example, a drawing of the crime scene can be useful to determine if the conditions are aligned with falling from the window or being thrown. This aspect of the activity may involve the contribution of the engineering or CAD design teacher. Geometry and trigonometry as well as physics and chemistry topics may easily be integrated into the PBL. Nevertheless, it is always essential to foster scientific process skills in any PBL, such as those employed by medical examiners during a death investigation. That is, they rule out the cause of death based on death scene characteristics, medical history, and other factors, and whatever is left that cannot be ruled out as the cause of death. Additionally, in real life, coroners, forensic examiners/investigators, and police officers are included in the process as case reporters; therefore, within this activity students should also be expected to write reports to meet learning objectives, thereby facilitating connections to the language arts class. At periodic intervals during the activity to check on learning, students should provide forensic reports that rule out possible causes of death. The final report should incorporate these preliminaries and provide a detailed hypothesis and a conclusion, so that students can demonstrate a clear final explanation, incorporating the mathematical and scientific processes to support their hypothesis and the conclusion.

\section{UNDERSTANDING PBL}

Given that this chapter is focused on assessment, it is important to connect the discussions in the book through an assessment model. The PBL Refresher Quick Quiz (see Appendix W) should be considered as a formative assessment task. Some answers are not obvious initially from just reading this book. In fact, PBL is much like riding a bicycle. No matter how many technical manuals one reads about riding a bike, one must still get on, fall off, and reflect on both actions and suggestions in order to master the task. What makes riding a bike so complex? It is not just one task. It is composed of many small tasks that must be mastered to enjoy success. You must be able to balance, coordinate your peddling and steering, remembering that maintaining your balance is easier as long as you are moving forward. Thus, remember how to brake and understand that loose gravel can result in a painful lesson. Just like riding a bike, PBL is not just one task but the interaction of several smaller tasks, including choosing learning outcomes, planning content, determining a scenario, writing the scenario, developing formative assessment tasks, creating rubrics, and designing summative assessment tasks. Then, once the PBL starts, two new tasks arise: managing the materials and students. Therefore, as one reads and implements their PBL, one will gradually be more confident about the answers to the PBL Refresher Quick Quiz. It is the only iterative process of reading about PBL and implementing it in the classroom required to make it a second nature. Only through practice is it possible to perfect one's teaching because it is the teachers' own experiences and reflections that offer the best opportunities to improve student achievement. 


\section{REFERENCES}

Andrade, H. G. (2000). Using rubrics to promote thinking and learning. Educational Leadership, 57(5), 13-18.

Andrade, H. G. (n.d.). Understanding rubrics. Retrieved from http://learnweb.harvard.edu/ALPS/thinking/docs/rubricar.htm.

Ashcroft, K., \& Palacio, D. (1996). Researching into assessment and evaluation in colleges and universities. London, UK: Kogan Page.

Boaler, J. (1998). Open and closed mathematics approaches: Student experiences and understandings. Journal for Research in Mathematics Education, 29, 41-62.

Brophy, J. (2004). Motivating students to learn (2nd ed.). Mahwah, NJ: Erlbaum.

Cavanaugh, S. (2006, November 15). Technology helps teachers home in on student needs. Education Week, 26(24), p.12.

Duncan, D. (2005). Clickers in the classroom: How to enhance science teaching using classroom response systems. San Francisco, CA: Addison Wesley/Pearson.

Falchikov, N. (1995). Peer feedback marking: Developing peer assessment. Innovations in Education and Teaching International, 32, 175-187.

Guskey, T. R. (2002). Does it make a difference?: Evaluating professional development. Educational Leadership, 59(6), 46-51.

Klum, G. (1994). Mathematics assessment. What works in the classroom. San Francisco, CA: Jossey-Bass.

Moursund, D. (n.d.). Part 7: Assessment. Retrieved June 1, 2012, from http://www.uoregon.edu/ moursund/PBL/part 7.htm.

O’Malley, K. J., Moran, B. J., Haidet, P., Seidel, C. L., Schneidr, V., Morgan, R. O., Kelly, P. A., \& Richards, B. (2003). Validation of an observation instrument for measuring student engagement in health professions settings. Evaluation \& Health Professions, 26(1), 86103

Patrick, P. (2009). Professional development that fosters classroom application. Modern Language Journal, 93, $280-287$.

Peckham, G., \& Sutherland, L. (2000). The role of self-assessment in moderating students' expectation. South African Journal for Higher Education, 14(1), 75-78.

Sanders, W. L., \& Rivers, J. C. (1996). Cumulative and residual effects of teachers on future students' academic achievement. Knoxville: University of Tennessee, Value-Added Research and Assessment Center.

Secretary's Commission on Achieving Necessary Skills. (2000). What work requires of schools: A SCANS report for America 2000. Washington DC: U.S. Department of Labor.

Simon, A., \& Boyer, E. G. (1969). Mirrors for behavior, An anthology of classroom observation instruments. ERIC document Reproduction No. 031613.

Solomon, G. (2003). Project-based learning: A primer. Technology \& Learning, 23(6), 20-30.

Stearns, L. M., Morgan, J., Capraro, M. M., \& Capraro, R. M. (2012). The development of a teacher observation instrument for PBL classroom instruction. Journal of STEM Education: Innovations and Research, 13(3), 25-34.

Taylor-Powell, E., \& Steele, S. (1996). Colleting evaluation data: Direct observation. Program development and evaluation. University of Wisconsin, Cooperative Extension-Program Development and Evaluation. Retrieved from http://cecommerce.uwex.edu/ pdfs/G3658_5.PDF

VanTassel-Baska, J., Feng, A. X., Brown, E., Bracke, B., Stambaugh, T., French, H., \& Bai, W. (2008). A study of differentiated instructional change over 3 years. The Gifted Child Quarterly, 52, 297-312.

Wright, R. J. (2008). Educational assessment: Tests and measurement in the age of accountability. Thousand Oaks, CA: Sage.

Zimmaro, D. M. (2004). Developing grading rubrics. Retrieved June 1, 2008, from the University of Texas at Austin, Division of Instructional Innovation and Assessment Web site: http://www.utexas.edu/academic/mec/research/pdf/rubricshandout.pdf

Robert M. Capraro

Department of Teaching, Learning and Culture

Texas A\&M University

Aggie STEM Center

M. Sencer Corlu

Graduate School of Education

Bilkent University, Turkey 